\title{
Effect of Nature and Amount of Polypropylene Composite Filler on the Productivity of Extruder with the Cylinder Equipped with Grooves
}

\author{
Volodymyr Krasinskyi', Volodymyr Moravskyi', Oleh Suberlyak', \\ Janusz Sikora², Tomasz Jachowicz ${ }^{2 *}$ \\ 1 Lviv Polytechnic National University, Department of Chemical Technology and Plastics Processing, Bandera \\ 12 St., 79013 Lviv, Ukraine, e-mail: vkrasinsky82@gmail.com \\ 2 Lublin University of Technology, Faculty of Mechanical Engineering, Department of Polymer Processing, \\ Nadbystrzycka 36 St. , 20-618 Lublin, Poland, \\ * Corresponding author's e-mail: t.jachowicz@pollub.pl
}

\begin{abstract}
The effect of grooves number in the feed section and screw length as well as filler nature and content on the productivity of single-screw extruder has been examined. Compositions based on polypropylene with glass fibers, talc and chalk were used for research. It is established that the number of grooves in the feed section and the length of the screw differently affect the productivity of a single screw extruder depending on the nature and content of the filler. This effect is shown to be most significant for polypropylene compositions with mineral powders (talc and chalk).
\end{abstract}

Keywords: extrusion, polypropylene, filler, extruder, screw, barrel design, active grooved feed section.

\section{INTRODUCTION}

The extrusion of polymeric materials using different extruders is characterized by a series of similar processes, namely: solid material movement and plasticization melt movement, mixing, dosing and ware forming. All these processes occur in different section along the barrel and they are described by different regularities[1, 15].

The first and most important section affecting the following extrusion process is the feed section $[3,9]$. In this section the polymer granules or powder from the hopper are fed to the screw interturn space under gravity and fill it. The conditions of granules (powder) movement from the hopper and filling of screw interturn space situated under the feeding hole are of great importance for the uniform movement of the material. The uniform dozing of the material from the hopper and filling of interturn space are necessary conditions ensuring the extrudate quality and defining the extruder productivity on the whole $[2,5,14]$.
It was determined by the experiments that the most effective movement of the material in the feed section is the movement, when material solid particles are packed in the fore-part of the screw channel and form so-called plug capable to move along the channel via piston motion mechanism $[4,7,17]$. The formation of solid plug from bulk material is possible in a case when the sufficient pressure is formed in the screw channel. The material moves as a result of screw surfaces movement relative to barrel due to the friction forces. In the extruder the friction force to barrel walls keeps the solid plug with screw from free rotation. Thus, the friction to barrel develops the moving force ensuring the material movement and the friction to the screw surface - retarding force. If the friction to barrel is equal to zero, the material will not move; if the friction to screw is equal to zero, the maximal movement of the material along the screw channel takes place $[3,11]$.

According to the fastest movement of the solid material the friction to barrel should be 
maximum and friction to screw - minimum. For this purpose a number of technical decisions are used. For example, to decrease the friction coefficient the chrome or nickel galvanic coatings are applied over the screw with its further polishing. Fluorine polymers are also used for such purpose. To increase the friction to barrel the surface should be maximally rough or grooves should be made on the internal surface.

The friction of material on the surface of the barrel is the driving force, which provides the movement of material. It is possible to change the interaction between the material and barrel walls due to the increase of surface roughness by applying the grooves of corresponding profile and size. The extruders with grooves in the feed section are widely used $[6,8]$. They are characterized by the following advantages compared with the extruders with smooth barrel [5]:

- greater flow capacity of the process;

- better stability of the extrusion process;

- low dependence of productivity from pressure changes.

However, they also have a number of disadvantages. The high friction coefficient to the barrel surface leads to the rapid and excessive growth of pressure and increases barrel wear that demands usage of more qualitative materials. Moreover, there is a great consumption of energy (till 30-40 $\%$ ) because of the necessity of the feed section intensive cooling. The energy consumption may be reduced due to the increase of cooling water temperature from 5 to $70^{\circ} \mathrm{C}$. In such a case the efficiency of energy usage increases by $45-80 \%$ [10]. One more disadvantage of extruder with grooves is the necessity to use the engine with higher torque compared with that for the extruder with barrel smooth walls. Such peculiarities result in the energy consumption increased by $10-25 \%$. The above-mentioned disadvantages ace typical of the barrels with grooves located parallel to the barrel axis. Using spiral grooves the energy consumption may be partially reduced [12].

Despite the advantages of the described feed section design it remains static during polymers extrusion and cannot be changed during equipment operation to affect the material movement and therefore, the extrusion process on the whole.

The grooves allowing changing the depth directly during equipment operation affect the material movement more efficiently. Such designs of the feed section are well-known and widely used [13]. Their advantages are: operation control of the feed section according to the material characteristics and screw regime; choice of the optimal groove depth during the equipment operation that allows controlling the whole extrusion process; automation of the process. Thus the regulated by depth grooves may be one more way to control and optimize the extrusion process (beside the temperature) allowing to extend the materials assortment and correct the extruder characteristics according to the material properties [16].

The classic single-screw extruders have limited possibilities to control the material dozing in the feed section: the insignificant effect of temperature change of the barrel or screw and change of screw grooves geometry. The latter is possible only while screw exchange [15].

On the basis of literature we conclude that the most convenient control method of material dozing is regulation of grooves depth in the feed section $[9,10]$. This method is the most fast and effective optimization method of extruder operation allowing affecting the material movement in the extruder. Using grooves it is possible to process various plastic masses on single-screw extruder and to correct machine characteristics in accordance with raw material properties [3].

\section{RESEARCH METHODS}

Polypropylene (PP) of the Moplen HP640J (LyondellBasell, the Netherlands) brand with $\mathrm{MFI}_{230 / 2.16}=3.2 \mathrm{~g} / 10 \mathrm{~min}$, Vicat softening point of $154{ }^{\circ} \mathrm{C}, \rho^{20}=0.900 \mathrm{~g} / \mathrm{cm}^{3}$, and tapped density $\rho_{\mathrm{t}}=$ $0.53 \mathrm{~g} / \mathrm{cm}^{3}$ was used in present work. Glass fiber, talc and chalk were used as the fillers. The filler content was varied from 10 to $50 \mathrm{wt} \%$.

For the investigations we used a single-screw extruder with barrel allowing changing the number of grooves in the feed section (Fig. 1). The extruder is equipped by screws of diameter $25 \mathrm{~mm}$ with the ratio $\mathrm{L} / \mathrm{D}$ is equal to 20,25 and 30 . The size of die flat slit is $20 \times 1 \mathrm{~mm}$. The extrusion process was executed at the following technological parameters: temperatures in the barrel section: feed $-160^{\circ} \mathrm{C}$, compression $-180^{\circ} \mathrm{C}$, metering $190^{\circ} \mathrm{C}$; die $-200^{\circ} \mathrm{C}$; screw speed $-25 \mathrm{rpm}$.

Different number of grooves in the feed section (Fig. 1a) is created using two types of shells: I - forms smooth cylindrical surface with the barrel (Fig. 1b); II - forms grooves in the cylindrical surface (Fig. 1c) by the depth of $2.3 \mathrm{~mm}$, length $94 \mathrm{~mm}$ and width $8 \mathrm{~mm}$. 


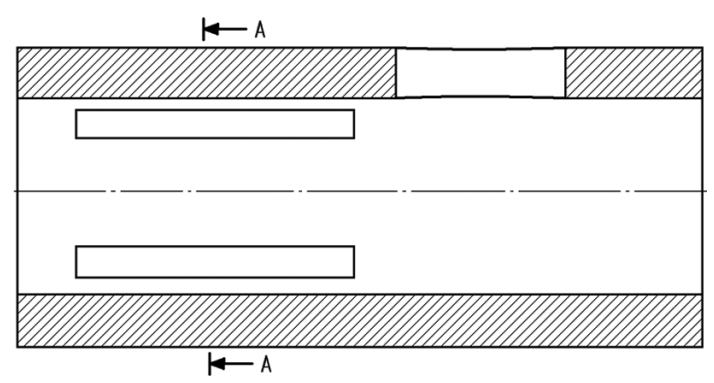

a)

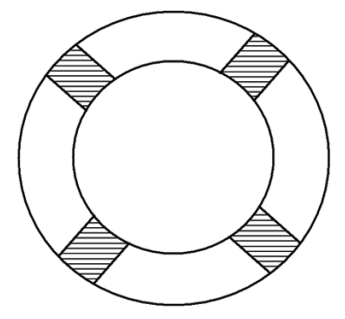

b)

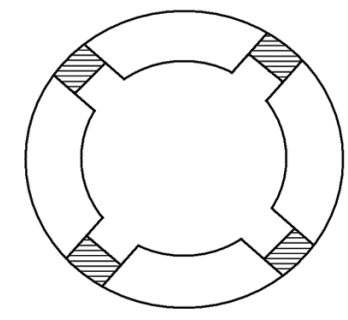

c)
Fig. 1. Location of vent grooves in barrel of extruder

\section{RESULTS AND DISCUSSION}

The extruder productivity was estimated by the weight of extrudate withdrawn after equal periods of time. The variable values affecting the extruder productivity in the first series of experiments were the number of grooves in the feed section and amount/nature of filler under fixed ratio L/D of the screw (25). In the second series of experiments we varied also L/D ratio (20 and 30).

The effect of filler amount and nature on the extruder productivity is represented in Figure 2.
Talc has the greatest influence on the extruder productivity. Glass fiber has the minor effect. We observe the slight increase in productivity under its content of more than $30 \mathrm{wt} \%$.

It is well-known [3] that extruder productivity is described by the following dependence:

$$
Q_{e x t}=F_{1} \cdot \alpha \cdot N-F_{2} \cdot \frac{\beta}{\mu_{e f}} \cdot \Delta \mathrm{P},
$$

where: $F_{1}$ and $F_{2}$ - coefficients taking account of screw geometry; $a$ and $b$-coefficients taking account of material rheological characteristics; $N$ - number of screw rotations; $\mu_{e f}-$ melt effective viscosity; $\Delta \mathrm{P}$ - pressure difference in the extruder.

According to the above-mentioned dependence the effect of filler content on the extruder productivity is explained by the increase of polymer melt viscosity with the increase of talc or chalk content under other equal parameters. The absence of the same effect while using glass fiber is caused by the orientation of fibrous filler due to which the melt viscosity is not sensitive to filler content. While using glass fiber in amount of $40-50 \%$ the slight increase in the productivity is explained by interaction between filler particles followed by the formation of physical bonds. This bonds is less stable compared with that of powdered fillers with the developed surface of the particles.

While analyzing the effect of grooves number and glass fiber content on the extruder productivity (Fig. 3) we observe an increase in

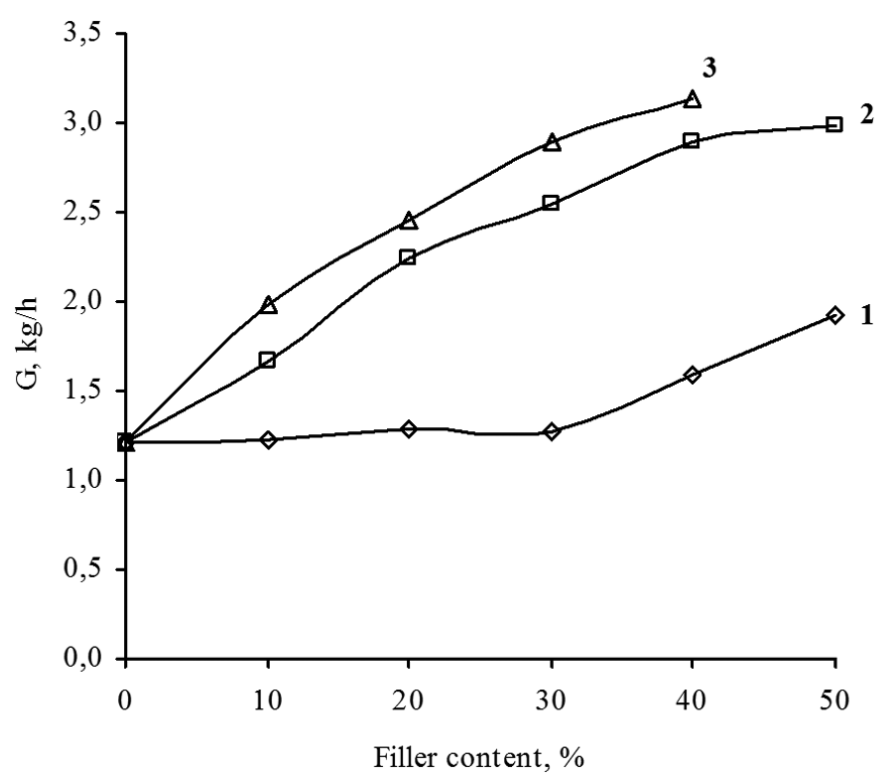

Fig. 2. Effect of filler nature and amount on the extruder productivity (number of grooves $0, \mathrm{~L} / \mathrm{D}=25$ ): 1 - glass fiber; 2 - chalk; 3 - talc 


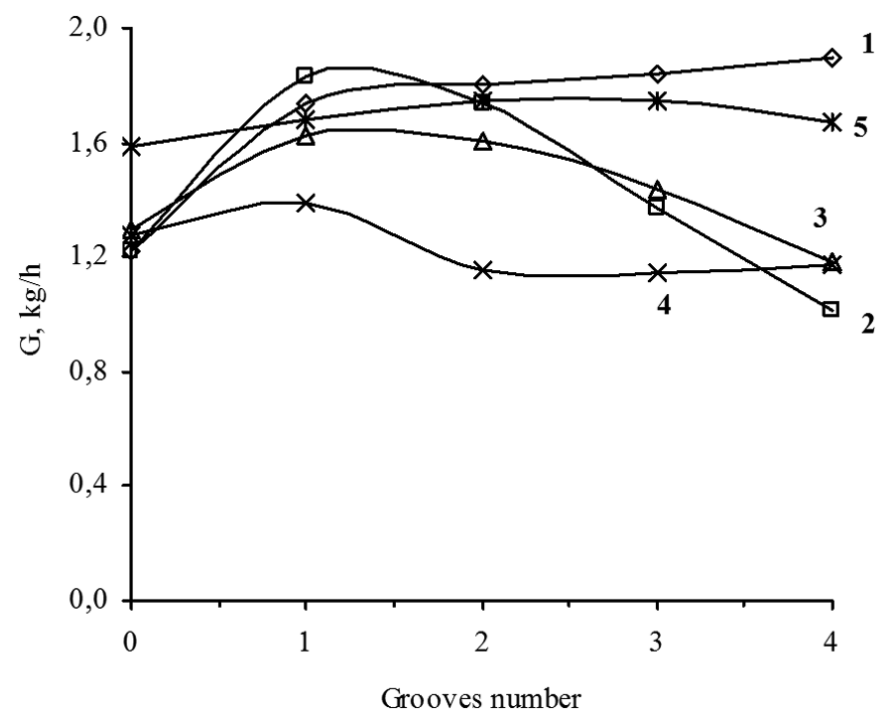

Fig. 3. Effect of grooves number and glass fiber content on the extruder productivity $(\mathrm{L} / \mathrm{D}=25)$ : glass fiber content $(\%): 1-0 ; 2-10 ; 3-20 ; 4-30 ; 5-40$

extruder productivity. It is achieved when one or two grooves are placed in the feed section of the barrel. However, for the composition with $40 \%$ content of the filler the decrease of productivity is minimal and its dependence on grooves number is almost the same as that for unfilled polypropylene.

The greatest effect of grooves number on the extruder productivity is observed at glass fiber content of 10-20\% (Fig. 3, curves 2 and 3). The further increase in glass fiber content insignificantly affects the productivity dependence on grooves number. It should be noted that we do not observe maximum of productivity for pure polypropylene when one groove is placed in the feed section. The increase in grooves number slightly increases the productivity and this dependence has linear character.

While using talc and chalk as fillers the effect of grooves number in the feed section on the extruder productivity is minor (Table 1). For the composition with $10 \%$ of chalk the extrusion process productivity increases with the increase of grooves number, the same as for pure polypropylene. With the further increase in chalk content the extruder productivity insignificantly depends on grooves number in the feed section.

The effect of grooves number on the extruder productivity is observed while processing the compositions with talc only for the compositions with filler content of 30 and $40 \%$. If for the compositions with $30 \%$ of talc the productivity decreases with the increase in grooves number, then for the compositions with $40 \%$ of talc it has the maximum.

The results of the second series of experiments concerning the effect of grooves number, screw length and chalk content on the extruder productivity are represented in Tables 2, 3 and 4. While using the screw with $\mathrm{L} / \mathrm{D}=20$ the productivity increases with the increase of chalk content (Table 2). For the screw with L/D ratio of 30 the productivity passes through the maximum at chalk content of $20-40 \%$ depending on grooves number. The effect of chalk content on the extruder productivity $(\mathrm{L} / \mathrm{D}=20)$ is explained

Table 1. Effect of grooves number and filler nature on the extruder productivity, $\mathrm{kg} / \mathrm{h}$ (nominator - chalk / denominator - talc)

\begin{tabular}{|c|c|c|c|c|c|c|}
\hline \multicolumn{2}{|c|}{} & \multicolumn{5}{|c|}{ Grooves number } \\
\cline { 3 - 7 } & & 0 & 1 & 2 & 3 & 4 \\
\hline \multirow{4}{*}{ Filler content, \% } & 10 & $1.67 / 2.47$ & $2.01 / 2.44$ & $2.05 / 2.50$ & $2.11 / 2.63$ & $2.28 / 2.58$ \\
\cline { 2 - 7 } & 20 & $2.24 / 2.35$ & $2.35 / 2.33$ & $2.41 / 2.45$ & $2.17 / 2.50$ & $2.09 / 2.38$ \\
\cline { 2 - 7 } & 30 & $2.40 / 3.21$ & $2.52 / 3.18$ & $2.57 / 3.06$ & $2.54 / 2.88$ & $2.70 / 2.59$ \\
\cline { 2 - 7 } & 40 & $2.90 / 3.14$ & $3.01 / 3.37$ & $3.08 / 3.64$ & $2.75 / 3.63$ & $2.82 / 3.14$ \\
\cline { 2 - 7 } & 50 & $2.98 /-$ & $3.17 /-$ & $3.22 /-$ & $3.32 /-$ & $3.06 /-$ \\
\hline
\end{tabular}


Table 2. Effect of grooves number, screw length and chalk content on the extruder productivity, $\mathrm{kg} / \mathrm{h}$ (nominator $-\mathrm{L} / \mathrm{D}=20 /$ denominator $-\mathrm{L} / \mathrm{D}=30$ )

\begin{tabular}{|c|c|c|c|c|c|}
\hline \multicolumn{2}{|c|}{} & \multicolumn{4}{c|}{ Grooves number } \\
\cline { 2 - 6 } & 0 & 0 & 1 & 2 & 3 \\
\hline \multirow{5}{*}{ Chalk content, $\%$} & $2.4 / 2.3$ & $2.6 / 2.5$ & $2.6 / 2.5$ & $2.7 / 2.6$ \\
\cline { 2 - 6 } & 10 & $2.9 / 2.5$ & $3.2 / 2.9$ & $3.0 / 2.9$ & $2.8 / 3.0$ \\
\cline { 2 - 6 } & 20 & $3.0 / 2.9$ & $3.3 / 3.4$ & $3.2 / 3.1$ & $3.1 / 3.2$ \\
\cline { 2 - 6 } & 30 & $3.3 / 3.0$ & $3.5 / 3.3$ & $3.5 / 3.4$ & $3.2 / 3.0$ \\
\cline { 2 - 6 } & 40 & $3.5 / 3.0$ & $3.7 / 3.2$ & $3.7 / 3.2$ & $3.6 / 2.9$ \\
\cline { 2 - 6 } & 50 & $4.0 / 3.0$ & $4.0 / 3.2$ & $3.8 / 3.1$ & $3.6 / 2.9$ \\
\hline
\end{tabular}

Table 3. Effect of grooves number, screw length and talc content on the extruder productivity, $\mathrm{kg} / \mathrm{h}$ (nominator $-\mathrm{L} / \mathrm{D}=20$ / denominator $-\mathrm{L} / \mathrm{D}=30$ )

\begin{tabular}{|c|c|c|c|c|c|}
\hline \multicolumn{2}{|c|}{} & \multicolumn{4}{|c|}{ Grooves number } \\
\cline { 3 - 6 } & 0 & 0 & 1 & 2 & 3 \\
\hline \multirow{3}{*}{ Talc content, \% } & $2.4 / 2.3$ & $2.6 / 2.5$ & $2.6 / 2.5$ & $2.7 / 2.6$ \\
\cline { 2 - 6 } & 10 & $2.9 / 2.6$ & $3.1 / 2.8$ & $3.0 / 2.7$ & $3.0 / 2.8$ \\
\cline { 2 - 6 } & 20 & $3.1 / 3.0$ & $3.3 / 2.9$ & $3.2 / 2.8$ & $3.3 / 3.2$ \\
\cline { 2 - 6 } & 30 & $3.3 / 3.4$ & $3.5 / 3.5$ & $3.5 / 3.8$ & $3.4 / 3.3$ \\
\cline { 2 - 6 } & 40 & $3.4 / 2.9$ & $3.8 / 3.3$ & $4.0 / 2.6$ & $3.9 / 3.0$ \\
\hline
\end{tabular}

by the growth of melt effective viscosity with the increase of filler content followed by the decrease of melt counterflow and the increase of productivity. While using the screw with $\mathrm{L} / \mathrm{D}=30$ the productivity maximum is caused by worsening of the material movement conditions (energy losses along the screw) after achievement of definite critical effective viscosity of the melt.

The effect of grooves number in the feed section on the extruder productivity is different using the screw with $\mathrm{L} / \mathrm{D}=20$ depending on chalk content in the composition. For pure polypropylene the productivity increases with the increase of grooves number. For the composition with $50 \%$ of chalk we observe the decrease of productivity. For the compositions with $10-40 \%$ of chalk the productivity passes through the maximum at the presence of one or two grooves. Using the screw with $\mathrm{L} / \mathrm{D}=30$ the general dependence is preserved but for the composition with $10 \%$ of chalk the productivity increases with the increase of grooves number (the same as fir pure polypropylene). For the composition with $50 \%$ of chalk we observe the maximum which is absent while using the shorter screw. Such dependence of the productivity on the grooves number is explained by better conditions of material mixing in the feed section with grooves. However it is observed only for pure polypropylene
$(\mathrm{L} / \mathrm{D}=20)$ and the composition with $10 \%$ of chalk $(\mathrm{L} / \mathrm{D}=30)$.

While studying polypropylene compositions with talc we obtained the similar results (Table 3). For the screw with $\mathrm{L} / \mathrm{D}=20$ the increase in talc content (the same as for chalk) increases the melt effective viscosity and productivity. For the screw with $\mathrm{L} / \mathrm{D}=30$ the increase in productivity is observed only at talc content less than $30 \%$. The further increase in filler content decreases the productivity. The effect of grooves number in the feed section on the extruder productivity is the same for both screws: the increase in grooves number increases productivity. Only for the composition with $40 \%$ of talc $(L / D=30)$ we observe the absence of mentioned dependence.

Glass fiber has less effect on the productivity as compared with chalk and talk (Table 4). Moreover, for the screw with $\mathrm{L} / \mathrm{D}=30$ we observe the decrease in productivity with the increase of glass fiber content. Such distinction is caused by the fibers orientation during melt flow that does not considerably increases the viscosity in contrast to the powder filler with developed surface (chalk and talc). Some increase in the productivity with the increase of glass fiber content is a result of possible interaction between fibers leading to the increased viscosity. It should be also noted that using the screw with $\mathrm{L} / \mathrm{D}=30$ the composition 
Table 4. Effect of grooves number, screw length and glass fiber content on the extruder productivity, $\mathrm{kg} / \mathrm{h}$ (nominator $-\mathrm{L} / \mathrm{D}=20 /$ denominator $-\mathrm{L} / \mathrm{D}=30$ )

\begin{tabular}{|c|c|c|c|c|c|}
\hline \multirow{2}{*}{} & \multicolumn{4}{|c|}{ Grooves number } \\
\cline { 2 - 6 } & 0 & 0 & 1 & 2 & 3 \\
\hline \multirow{4}{*}{$\begin{array}{l}\text { Glass fiber } \\
\text { content, } \%\end{array}$} & 10 & $2.4 / 2.3$ & $2.6 / 2.5$ & $2.6 / 2.5$ & $2.7 / 2.6$ \\
\cline { 2 - 6 } & 20 & $2.4 / 2.4$ & $2.5 / 2.3$ & $2.5 / 2.1$ & $2.6 / 2.6$ \\
\cline { 2 - 6 } & 30 & $2.7 / 1.9$ & $2.4 / 1.7$ & $2.5 / 1.7$ & $2.5 / 1.8$ \\
\cline { 2 - 6 } & 40 & $3.9 /-$ & $2.4 /-$ & $2.6 /-$ & $2.4 /-$ \\
\cline { 2 - 6 } & 50 & $2.6 /-$ & $2.8 /-$ & $3 /-$ & $3.1 /-$ \\
\hline
\end{tabular}

with $30 \%$ of glass fiber cannot be processed at the experimental equipment. The reason is the considerable increase in energy consumption using longer screw because of the friction.

\section{CONCLUSIONS}

Thus we conclude that extruders equipped by the feed section with grooves affect the extrusion process. Also it is possible to change the extruder characteristics depending on the material. The effect of grooves number on the extruder productivity considerably depends on filler nature and content in the polymeric composition. Thus, the significant effect is observed for the compositions with fine powdered filler (talc and chalk) and minor effect - for the fibrous filler (glass fiber).

\section{REFERENCES}

1. Alfaro J.A.A., Grünschloß E., Epple S., Bonten C. Analysis of a Single Screw Extruder with a Grooved Plasticating Barrel - Part I: The Melting Model. International Polymer Processing, 2015, 30 (2), 284-296.

2. Donovan R.C. A theoretical melting model for plasticating extruders. Polymer Engineering and Science, 1971, 11 (3), 247-257.

3. Gaspar-Cunha A., Covas J.A. The plasticating sequence in barrier extrusion screws part I: Modeling. Polymer Engineering \& Science, 2013, 54 (8), 1791-1803.

4. Gaspar-Cunha A., Covas J.A. The Plasticating Sequence in Barrier Extrusion Screws Part II: Experimental Assessment. Polymer-Plastics Technology and Engineering, 2014, 53 (14), 1456-1466.

5. Głogowska K., Sikora J.W., .Majewski Ł. New concepts for the active grooved-feed section extruder. Industry 4.0, 2019, 4 (5), 237-240.
6. Gramann P.J., Rauwendaal C., Osswald T.A. and Tellez G. Kinematics of Flow in Single Screw Extruders. International Polymer Processing, 1999, 8 (4), 327-333.

7. Lafleur P.G. and Vergnes B. Single-Screw Extrusion in Polymer Extrusion, 2014, 37-108.

8. Long P., Minguin J., Ping X., Zhiming J. The solids conveying mechanism for helically grooved singlescrew extruders. Journal of Wuhan University of Technology-Mater. Sci. Ed., 2013, 28 (4), 693-700.

9. Mikulionok I.O. Screw extruder mixing and dispersing units. Chemical and Petroleum Engineering, 2013, 49 (1-2), 103-109.

10. Noriega M.P., Osswald T.A. and Ferrier N.J. In-Line Measurement of the Polymer Melting Behavior in Single Screw Extruders. Journal of Polymer Engineering, 2004, 24 (6), 557-578.

11. Osswald T.A., Noriega M.D., Gramann P.J. and Davis B.A. Grooved Feed Single Screw Extruders. Polymer Engineering \& Science, 1998, 38 (7), 1199-1204.

12. Peng F., Vogt B.D. and Cakmak M. Complex flow and temperature history during melt extrusion in material extrusion additive manufacturing. Additive Manufacturing, 2018, 22, 197-206.

13. Rautenbach R, Peiffer H. Model Calculation for the Design of the Grooved Feed Section of Singlescrew Extruders. Kunststoffe-German plastics, 1982, 72 (3), 6-11.

14. Rauwendaal C., Sikora J. The Adjustable Grooved Feed Extruder. Plastics Additives \& Compounding, 2000, 2 (6), 26-30.

15. Rauwendaal C. Polymer extrusion. Munich: Carl Hanser Verlag, 2014, 950.

16. Sikora J.W., Samujlo B., Stasiek A, Tor-Świątek A. The Mechanical Properties of Plasticized PVC Processed in an Extruder with a Modified Feed Zone. International Polymer Processing, 2015, 30 (3), 359-365.

17. Wilczyński K., Nastaj A., Wilczyński K.J. Melting Model for Starve Fed Single Screw Extrusion of Thermoplastics. International Polymer Processing, 2013, 28 (1), 34-42. 